Chairman : Dr H. M. SINCLAIR, Laboratory of Human Nutrition (University of Oxford), South Parks Road, Oxford

\title{
UNICEF assistance for child nutrition
}

\section{By The Secretariat of The United Nations Children's Fund (UNICEF), United Nations Building, New York}

By the end of this year, after 9 years of operation, UNICEF will have shipped, or allocated for shipment, a total of about $700,000,000 \mathrm{lb}$. of dried skim milk. In addition, it will have allocated the equivalent of over $f 3,500,000$ for milk-conservation projects. The purpose of this paper is to present some points of interest from a nutritional point of view on how and why this was done, together with some comments on UNICEF's interest for the future in child nutrition.

\section{Co-operation with FAO and WHO}

First, it may be well to supplement briefly the comments by Dorolle (1956), Aykroyd (1956) and Burgess (1956) on the relationship of UNICEF with FAO and WHO. A function of all three agencies is to aid government programmes that result in benefits to children; for UNICEF, however, it is the exclusive function. UNICEF aid to these programmes is primarily in the form of imported supplies and equipment; the aid of the other agencies is primarily in the form of technical assistance. This clear-cut difference in primary emphasis simplifies the question of collaboration. The problem is not one of principle, or duplication of aid, but rather of assuring the most effective relationship between the different types of aid given by each of the agencies.

In all the UNICEF activities described in this paper UNICEF has relied upon FAO and WHO for assurance that its overall policies and planning are based upon sound technical ground. The foundation for the work of UNICEF is based both upon the broader activities of these agencies and upon the specific technical aid which they give UNICEF and the assisted governments in planning and implementing individual programmes.

\section{Early child-feeding programmes}

When UNICEF was established by the United Nations General Assembly in December 1946, the path of action before it in the field of child nutrition was clear. As its first priority, UNICEF was to continue the work of the United Nations Relief and Rehabilitation Agency in aiding war-devastated countries, mainly in Europe, to carry on supplementary child-feeding programmes. 
On the advice of a group of nutritionists and paediatricians at a meeting convened by FAO and WHO in July I947 (FAO/WHO: Interim Commission, I947), the major nutritional principle adopted was to limit UNICEF aid to the provision of supplementary foods of high nutritive value, especially foods rich in protein. Emphasis was placed on the provision of dried skim milk, which was economical, easy to transport, and relatively easy to prepare for consumption. Also to be provided were foods such as fats, meats, fish and cheeses, and, during the winter months, fish-liver oil capsules. The governments were expected to provide out of local foods (usually cereals, potatoes, and vegetables) an amount of calories matching UNICEF foods. The total supplementary meal from both sources provided about 500-600 Cal. daily, mostly to schoolchildren.

The main problems, administrative rather than technical in nature, were those inherent in a bulk-supply operation which required distribution through thousands of small schools, nurseries, children's institutions, and the like. The programmes required considerable effort on the part of the governments in organizing a distribution system, in finding sufficient funds (often national, regional and local), and in enlisting thousands of volunteer workers through bodies such as local private societies, parent-teacher groups and local committees.

The peak was reached early in $195^{\circ}$ with about 6 million beneficiaries in twelve countries (UNICEF, I95I). With the general improvement of the food situation in Europe, a tapering-off of UNICEF aid began, and by mid-I95 I only four countries in Europe were continuing to receive UNICEF food.

\section{Next steps}

UNICEF had not only given an impetus to child-feeding programmes but had popularized the importance of milk in children's diets and had focused attention generally on child nutrition. The next step was to aid the countries in establishing permanent facilities for collecting, conserving, and distributing safe milk from local sources to replace the imported supplies, and to do it in such a way that the countries would be able to provide free or low-cost milk to large numbers of children. UNICEF provided the imported equipment required for drying and pasteurizing plants; the governments provided the buildings, auxiliary equipment, machinery and labour, averaging in value about five times more than the UNICEF contribution.

As with child-feeding programmes, the approach presented no fundamental problems from a nutritional point of view. There was no dearth of other problems, however, including: the location of the plant site; the costs of production; the practical economics of assuring free or subsidized distribution to children on as large a scale as possible; the financing and management of the plants; construction and engineering requirements; the training of local staff to operate the plants; the control of milk quality.

The original time schedules proved to be overoptimistic, and in some countries the feeding programmes were discontinued or drastically reduced before milk became available from the plants. 
Nevertheless, despite this difficulty, a recent survey of experience with UNICEFaided milk-conservation projects in a number of European countries showed an impressive enthusiasm over the results: free milk distribution and national childfeeding schemes had been encouraged; milk was being readily accepted by children; a high proportion of the fluid milk sold was consumed by nursing and pregnant mothers and by children under 15 ; and the quality of milk was steadily improving.

At the same time, there was considerable evidence that the provision of a steady market for raw milk had encouraged farmers to improve the milk yield by better methods of selection and animal husbandry generally. For all these developments the governments are increasingly calling upon the advice of FAO. Ministries of agriculture have used the stimulus of the programme to stress the necessity for cleanmilk production on the farms, and ministries of health have used it to enforce sanitary codes and laws affecting milk.

The effects of the milk-conservation projects in providing a focal point for improving the dairy industries made possible a reduction in the cost of safe milk and opened up the possibility of an increase in the milk consumption generally as part of the normal diet (UNICEF, r955a).

\section{Child feeding in underdeveloped countries}

Beginning in $195 \mathrm{I}$, UNICEF shifted the main emphasis of its work to underdeveloped countries (beginning in Asia and Asia Minor and then including Central and South America and, more recently, Africa). The main problem was to find what could be done most effectively with the limited resources available to UNICEF.

The bulk of UNICEF aid has been for the control of communicable diseases largely affecting children (mularia, tuberculosis, yaws, syphilis) and for maternal- and child-welfare services (mainly to rural centres). As with the school-feeding programmes in Europe, there was sufficient experience and technical knowledge to indicate a clear path of action by which UNICEF supplies and WHO technical advice could be combined to aid government programmes in these fields along lines that were economically practical and gave reasonable assurance of effective longrange results.

Considerably less apparent were the possibilities for the UNICEF type of supply action in the field of child nutrition. It was obvious from the moderate funds at the disposal of UNICEF, the enormous numbers of children involved, and the limited financial and distribution facilities of most governments, that mass supplementary child-feeding programmes were not practical. With some doubts about its results, the UNICEF Executive Board agreed to provide milk for some small-scale demonstration school-feeding programmes in certain countries (notably in Central America) with the hope that the initial stimulus would lead to workable programmes which would be expanded later. The basic point of view dominating the thought of the UNICEF Executive Board was the new mandate given to UNICEF to concentrate on projects of long-range value, and the realization that the temporary importation of milk did not offer a long-term solution to the child-nutrition problems of underdeveloped countries. 
An important new element, however, entered the picture in 1953 with the availability of U.S. surplus skim-milk powder at the considerably reduced cost, including ocean freight, of $2 \cdot 5 \mathrm{c}$. $/ \mathrm{lb}$. (This year, the milk is available free at the port of exit, involving only ocean freight costs of $\mathrm{I} \cdot 5 \mathrm{c}$./lb.) Opinion in the UNICEF Executive Board was divided on the extent to which UNICEF should avail itself of the milk. The Board was influenced in part by its experience in $1949-50$ when some 42 million lb. of U.S. surplus skim-milk powder, available at a low cost, had been shipped by UNICEF to some fifteen countries in Asia. With the exception of one country (the Philippines), the distribution left virtually no continuing programme.

There was no disagreement in the Board on use of milk to meet emergencies such as those caused by natural disasters or to meet relief needs of children and mothers in situations such as in Korea. Aside from this, some Board members stressed that UNICEF should provide milk only for projects that gave real promise of permanent impact. Others stressed, however, that it was often difficult to distinguish in a clearcut fashion at the outset between short- and long-range impact and that some calculated risk should be taken, since the short-range projects often laid the basis for subsequent expanded long-range programmes. In this connexion, quite favourable experience that was emerging from the Central American demonstration feeding projects was cited (UNICEF, I952). An additional consideration was the awareness that the disposal of surplus milk through UNICEF methods of distribution was one of the more desirable methods of surplus disposal, since it did not replace local production or interfere with international trade.

The differences, which were primarily those of emphasis, were considerably narrowed when it became apparent that surplus milk powder would be available to UNICEF at least through 1956 and that it could be used in feeding programmes through I958. This gave the possibility of establishing programmes of at least 4 years' duration, a time which in many places seemed sufficient for the programmes, if well planned, to become both a stimulus and a nucleus for more permanent solutions.

In 1954, UNICEF approved allocations involving some in 3 million $1 \mathrm{~b}$. of dried skim milk for child feeding, representing about $15 \%$ of the world's yearly export in dried milk. About 40 million $1 \mathrm{~b}$. were for emergency relief, about $4 \mathrm{I}$ million for school-feeding programmes, and 32 million for distribution through maternal-and child-welfare centres. UNICEF is currently providing skim milk to some fifty countries for programmes reaching about $2,700,000$ children.

There is considerable difference in the nutritional objective of distribution carried on through maternal- and child-welfare centres and through school-feeding programmes. Through the centre it is possible to reach pregnant and nursing mothers as well as children during the crucial postweaning and preschool ages. As Aykroyd ( $195^{6}$ ) has pointed out, protein malnutrition in the $\mathrm{I}-5$ year age group is most serious in terms of future health. The centres are mostly beginning their work, and their professional staffs and budgets are usually overburdened. However, on a selective basis it is possible for them to treat individual cases of malnutrition through protein feeding, as part of their regular health activities, particularly if there is volunteer 
help available to take over the physical burden involved in the milk distribution.

It is important that the centres include in their distribution programmes an adequate educational effort with practical instruction in milk handling as well as general nutritional information. As Aykroyd has pointed out, mothers can often be taught to make changes in feeding practices that will carry the child through the postweaning period in reasonably good health.

The merits of school-feeding programmes are well known as a means of showing the value of proper nutrition to children and their parents and of stimulating community interest and organizational arrangements for better child nutrition. Schoolfeeding programmes, however, are not at present economically feasible in every country, nor are their merits inherent in every programme. To assure these benefits, the following criteria are used in accepting programmes for aid:

(a) UNICEF will assist school-feeding programmes only where sufficient local resources are available to run them satisfactorily and where there is a reasonable prospect of continuation in some form after the end of UNICEF aid.

(b) Concomitant effort to locate and use local sources of high-protein foods should be a part of every plan of operations.

(c) Every programme should include some local matching foods such as bread and fruit.

(d) Effort should be made for organized instruction for mothers and children on the importance of good nutrition, the value of the milk and other foods being distributed, and ways in which the individual family can improve the nutrition of their children with locally available foods.

(e) The maximum help from local governments (municipal) and the voluntary participation of parents should be sought (e.g. in providing fire-wood, utensils and local foods).

(f) UNICEF is not interested in assisting elaborate school-lunch programmes in capital cities at such a high level of sophistication that they cannot be repeated in other less favoured parts of the country. This does not mean that capital cities are ruled out, but it does mean that urban programmes should be simple and that rural areas should be included in feeding programmes at the same time.

As a result of recommendations made to the UNICEF Board in March I955 by Dr C. G. King, who made a survey in Central America on behalf of both UNICEF and FAO (UNICEF, I955b), the Board decided, on an experimental basis, to increase the daily milk ration in UNICEF-aided programmes in Central America from $40 \mathrm{~g}$ skim-milk powder/day to from 50 to $80 \mathrm{~g}$. This is to be done with special emphasis on finding effective channels of distribution to postweaning and preschool children. In addition to the use of maternal- and child-welfare centres, where available, attempts will be made to use rural schools for distribution in conjunction with a nutrition-education programme designed to reach family units, especially the mothers. If this experiment is successful, the same approach could be applied in other areas of the world. This would apply particularly for the ration of milk going to nursing mothers and preschool children. 


\section{Milk conservation in underdeveloped countries}

As UNICEF turned its attention to underdeveloped areas, the possibilities for adapting its European experience in milk conservation did not appear bright, since in most countries there seemed to be no immediate prospects for the development of a dairy industry. Upon detailed expert examination, however, it became clear that the potentialities were greater than originally assumed. The common belief that milk production was economically possible only in temperate zones was reexamined in the light of solutions, now possible, of problems of livestock disease, nutrition and breeding, and insect control. In a number of tropical areas it was found that milk supplies for human consumption were low, not so much because of the inability to produce milk but because of the limiting factor of time in the collection and distribution of the perishable milk. Though this was a difficult problem, modern milk-handling equipment has made it possible.

It was recognized that, with lower milk supplies to begin with, less general knowledge about the value of milk in the diet, less experience within the countries, a hot climate, and a very low income per head, the element of risk was greater than it had been in Europe and each proposed new project needed to be preceded by especially careful surveys and advance planning. Progress has been made, however, and up to now UNICEF has approved aid for sixteen drying plants in underdeveloped countries (one in Africa, two in Asia, one in the Eastern Mediterranean area, and twelve in Central and South America), and thirteen fluid-milk plants (two in Asia, eight in the Eastern Mediterranean area, and three in Central and South America). Two of the drying plants (in Nicaragua and Chile) are in operation.

Unlike in Europe, there is a preference for milk-drying rather than fluid-milk plants whenever circumstances are appropriate. The dried-milk product has distinct advantages in government-subsidized distribution to larger numbers, since a drying plant can utilize cheap milk far from cities, and its product can be used in schools and maternal- and child-welfare centres all over the country.

Though it is still too early for a definitive evaluation, experience thus far has encouraged UNICEF to approach the possibilities of milk conservation in underdeveloped countries in a far more positive spirit than would have been thought possible 4 or 5 years ago.

\section{Looking towards the future}

The current UNICEF policy on the use of milk has evolved against a background of availability of surplus skim milk, a situation which will not last indefinitely. For this reason, UNICEF has become very much interested in the development of locally feasible methods of producing fish flour and vegetable proteins in a form suitable for assimilation by young children.

Tests of acceptability of fish flour sponsored by FAO with fish flour supplied by UNICEF are now under way in a number of countries, and UNICEF will be in a position at its next session, in September, to aid for the first time a fish-flour plant (in Chile). 
In Indonesia, UNICEF is aiding in the erection of a plant to produce dried vegetable milk based upon the soya bean as a food for infants and toddlers, to be distributed through maternal- and child-welfare clinics and hospitals. The plant is expected to go into operation late this year. As with other foods that require industrial processing, this approach must be limited in its scope because the costs involved are comparable to those of milk production.

However, large amounts of nutritious food that could be processed for children are contained in by-products of the edible-oil industry, which are at present used for animal feeding. Practical methods for making these protein-rich foods suitable for child feeding and at low cost are under careful investigation, for example making a flour from the press cake remaining after commercial oil extraction from groundnuts, cottonseed, sesame or sunflower-seed. These refined high-protein products could then be incorporated in local foods.

A first step toward uncovering new food possibilities is to evaluate the research work already done by governmental, industrial and private research laboratories to determine what new techniques can be economically and effectively used to make locally produced high-protein products suitable for child-feeding purposes. There also appears to be the need for a period of laboratory development, perhaps by various nutrition institutes, to find the right recipe nutritionally and to produce some pounds of the new food mixture for testing purposes. In some instances it will be necessary to prove laboratory findings by pilot-plant methods and by conducting acceptability tests on a fair-size scale before industrial methods are instituted. The transition to full-scale production capable of putting out a high-quality, low-cost product acceptable to children might then require UNICEF aid.

UNICEF, of course, realizes that the majority of the malnourished children of the world cannot be fed on factory products and that a more fundamental solution lies in teaching the rural family, especially the mother, to make the best use of available and possible local food resources. This is a complex problem, since it involves first of all knowing what ought to be done in this direction country by country and locality by locality. It also requires a considerable effort on the part of agricultural, educational, and public-health authorities. In this effort there would be need for further international aid.

At its last session, in March of this year, the UNICEF Executive Board reviewed possibilities for future work in the field of child nutrition. The general feeling was one of being on the threshold of new developments, only the bare outlines of which can presently be seen. It was encouraging that new knowledge on problems of nutritional balance and clinical aspects of malnutrition appears available now for laying a solid basis for future work; and that encouraging local experiments have shown that child nutrition can be improved by fairly simple, although carefully chosen, means within the context of a steady progress in related fields such as agricultural economics, home economics, nutrition education. The Executive Board concluded that 'significant progress can be made in the years ahead if international action is intensified' (UNICEF, 1955c). 


\section{Nutrition programmes currently assisted by UNICEF}

\author{
AFRICA (2) \\ Gambia \\ Nigeria
}

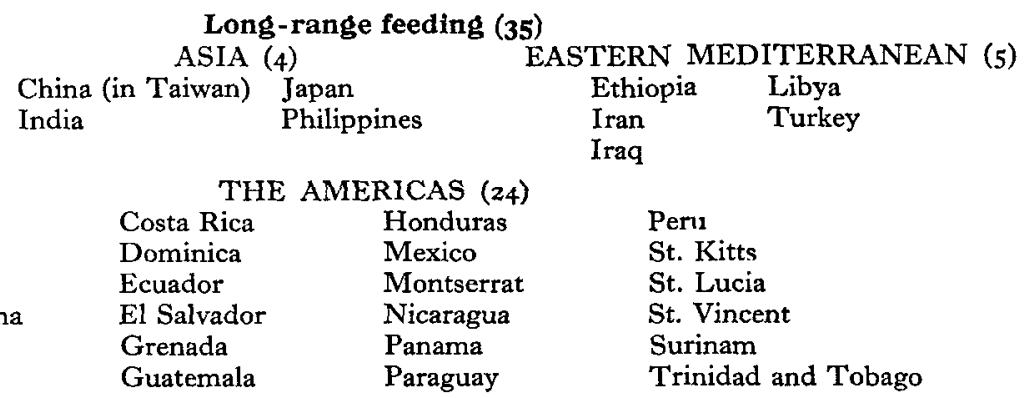

Antigua
Bolivia
Brazil
British Guiana
Chile
Colombia

AFRICA (1) Nigeria

Milk and food conservation (22)

$\begin{array}{lcc}\text { ASIA (2) } & \text { EASTERN MEDITERRANEAN (5) } \\ \text { India } & \text { Egypt } & \text { Israel } \\ \text { Indonesia* } & \text { Iran } & \text { Turkey } \\ & \text { Iraq } & \end{array}$

EUROPE (4)

\begin{tabular}{lcc} 
& Finland & \multicolumn{2}{c}{ Italy } \\
& Yreece & \multicolumn{2}{c}{ Yugoslavia } \\
Bolivia & & THE AMERICAS (IO) \\
Brazil & Costa Rica & Guatemala \\
Chile & Ecuador & Mexico \\
Colombia & El Salvador & Nicaragua
\end{tabular}

Note: In addition, UNICEF milk and vitamins are distributed through maternal- and child-welfare programmes in some forty-five countries and in emergency relief programmes in seven countries.

* Dried vegetable milk based upon the soya bean.

\section{REFERENCES}

Aykroyd, W. R. (1956). Proc. Nutr. Soc. 15, 4.

Burgess, R. C. (1956). Proc. Nutr. Soc. 15, 13.

Dorolle, P. (1956). Proc. Nutr. Soc. 15, r.

FAO/WHO: Interim Commission (1947). Report on Child Nutrition. Washington, D.C.: Food and Agriculture Organization of the United Nations.

UNICEF (195I). Final Report of the First Executive Board, I I December 1946-31 December 1950. U.N. Document E/ICEF/I60.

UNICEF (1952). UNICEF Assistance for Child Feeding Programmes in Central America. U.N. Document $\mathrm{E} / \mathrm{ICEF} / \mathrm{i} 86$.

UNICEF (1955a). Some Aspects of Milk Conservation Experience. U.N. Document E/ICEF/281/Add.7. UNICEF (1955b). Recommendations for Further Development of UNICEF-Aided Programmes in Central America and Panama-A Report by Dr C. G. King. U.N. Document E/ICEF/293.

UNICEF (1955c). Report of the Executive Board, March 1955. U.N. Document E/ICEF/294, para. 69. 